\title{
miR-370 inhibits the oxidative stress and apoptosis of cardiac myocytes induced by hydrogen peroxide by targeting FOXO1
}

\author{
ZHANJUN QIU ${ }^{1-5^{*}}$, LEI WANG $^{2 *}$, HUAIYU MAO $^{6}$, FENG XU $^{1,3-5}$, BIN SUN $^{7}$, \\ XINBAO LIAN $^{2}$, JIALI WANG ${ }^{1,3-5}$, FENG KONG ${ }^{8}$, LINA WANG $^{9}$ and YUGUO CHEN ${ }^{1,3-5}$ \\ ${ }^{1}$ Department of Emergency Medicine and Chest Pain Center, Affiliated Qilu Hospital of Shandong University, \\ Jinan, Shandong 250012; ${ }^{2}$ Department of Emergency and Critical Care Medicine, Affiliated Hospital of \\ Shandong University of Traditional Chinese Medicine, Jinan, Shandong $250014 ;{ }^{3}$ Clinical Research Center for Emergency \\ and Critical Care Medicine of Shandong Province, Institute of Emergency and Critical Care Medicine of \\ Shandong University; ${ }^{4}$ Key Laboratory of Emergency and Critical Care Medicine of Shandong Province, \\ Key Laboratory of Cardiopulmonary-Cerebral Resuscitation Research of Shandong Province; ${ }^{5}$ The Key Laboratory of \\ Cardiovascular Remodeling and Function Research, Chinese Ministry of Education, Chinese Ministry of \\ Health and Chinese Academy of Medical Sciences; The State and Shandong Province Joint Key Laboratory of \\ Translational Cardiovascular Medicine; Qilu Hospital of Shandong University, Jinan, Shandong 250012; ${ }^{6}$ Department of \\ Emergency Medicine, The Second People's Hospital of Dongying, Dongying, Shandong 257335; ${ }^{7}$ Department of \\ Emergency Medicine, Yidu Center Hospital of Weifang, Weifang, Shandong 262500; Departments of ${ }^{8}$ Central Laboratory \\ and ${ }^{9}$ Clinical Laboratory Medicine, The Second Hospital of Shandong University, Jinan, Shandong 250033, P.R. China
}

Received January 15, 2019; Accepted July 5, 2019

DOI: $10.3892 / \mathrm{etm} .2019 .7908$

\begin{abstract}
Myocardial infarction, one of the main factors that threatens human health, leads to cardiac cell death. Myocardial cells suffer ischemia and hypoxia for a long period of time, which can lead to irreversible cell death or apoptosis and cardiac dysfunction. MicroRNAs (miRs) have been reported to play an important role in a wide range of biological processes in cardiac myocytes, which respond to inflammation and oxidative stress. The aim of the present study was to investigate the effect of miR-370 on oxidative stress and apoptosis of cardiac myocytes in ischemic $\mathrm{H} 9 \mathrm{C} 2$ cells induced by hydrogen peroxide $\left(\mathrm{H}_{2} \mathrm{O}_{2}\right)$. $\mathrm{H} 9 \mathrm{C} 2$ cells were cultured and treated with different concentrations of $\mathrm{H}_{2} \mathrm{O}_{2}$ solution. Then,
\end{abstract}

Correspondence to: Dr Yuguo Chen, Department of Emergency Medicine and Chest Pain Center, Affiliated Qilu Hospital of Shandong University, 107 Wenhuaxi Road, Jinan, Shandong 250012, P.R. China

E-mail: cyguo121@163.com

Dr Lina Wang, Department of Clinical Laboratory Medicine, The Second Hospital of Shandong University, 247 Beiyuan Road, Jinan, Shandong 250033, P.R. China

E-mail:wlna121@163.com

${ }^{*}$ Contributed equally

Key words: myocardial infarction, microRNA-370, Forkhead box O1, oxidative stress, apoptosis cells were transfected with miR-370 mimic or negative control (NC) mimic, small interfering (si)-RNA-Forkhead box O1 (FOXO1) and NC siRNA. A Cell Counting Kit-8 and flow cytometry assay were conducted to detect cell viability and cell apoptosis. The expression of oxidative stress associated factors were detected by ELISA. The levels of miR-370 and FOXO1 were examined using western blotting and reverse transcription-quantitative PCR. A luciferase reporter gene assay was performed to verify whether FOXO1 was a target gene of miR-370. The results revealed that miR-370 expression was downregulated and FOXO1 expression was increased in $\mathrm{H} 9 \mathrm{C} 2$ cells induced by $\mathrm{H}_{2} \mathrm{O}_{2}$. Additionally, FOXO1 was proven to be a target of miR-370. The ELISA and flow cytometry assay revealed that $\mathrm{miR}-370$ overexpression and FOXO1 silencing reversed $\mathrm{H}_{2} \mathrm{O}_{2}$-induced oxidative stress and apoptosis. The results indicated that miR-370 could inhibit the oxidative stress and apoptosis of $\mathrm{H} 9 \mathrm{C} 2$ cells induced by $\mathrm{H}_{2} \mathrm{O}_{2}$ by targeting FOXO1. Therefore, miR-370 may be a new therapeutic target for ischemic heart disease.

\section{Introduction}

Cardiovascular disease has the highest rates of morbidity and mortality worldwide (1), as it results in cardiac remodeling which is associated with the potential pathological changes observed in most heart diseases, including heart failure, myocardial infarction (MI), atrial fibrillation, atherosclerosis (AS) and ischemia/reperfusion (IR) (2). MI is one of the main factors that threatens human health and causes cardiac cell death (3). During MI, myocardial cells suffer ischemia and hypoxia for a long period of time, which can lead to irreversible 
cell death or apoptosis and cardiac dysfunction (4). Reducing apoptosis of myocardial cells can improve cardiac function and cardiac remodeling process after MI (5).

Oxidative stress and apoptosis play a crucial role in the development of cardiovascular diseases (6). The balance between oxidants and antioxidants plays a vital role in maintaining normal biological function. Excessive levels of reactive oxygen species cause serious damage to cardiac myocytes, which can damage the oxidation-antioxidant equilibrium system (7). In addition, further damage can lead to apoptosis (8). Therefore, mitigation of oxidative stress and direct intervention in inhibiting apoptotic pathways can provide potential molecular targets for treatment $(9,10)$.

MicroRNAs (miRs/miRNAs) are a class of non-coding RNA molecules, 18-24 nucleotides long, that are endogenous, conserved and can degrade or inhibit the translation of their target mRNAs, thereby regulating gene expression and playing an important role in a wide range of biological processes (11-13). There is an increasing body of evidence that has indicated the important role of miRNAs in a number of types of cardiac diseases (14-16). Although the functions of miR-370 in different diseases are controversial, miR-370 has always been considered to be a tumor suppressor in a number of types of human cancers. For example, miR-370 was downregulated in endometrioid ovarian cancer by regulating endoglin to suppress cell proliferation and induce cell apoptosis (17). Feng et al (18) illustrated that there was significant downregulation of miR-370 in gastric cancer tissues and cells targeting progestin and AdipoQ receptor family member 4. It has been reported that the expression of miR-370 was decreased in AS models and upregulation of miR-370 could inhibit vascular inflammation and oxidative stress (19). Furthermore, the expression of miR-370 in the myocardium was reported to decrease after MI (20). However, the expression of miR-370 in cardiac myocytes after induction with hydrogen peroxide $\left(\mathrm{H}_{2} \mathrm{O}_{2}\right)$ and the corresponding mechanisms on oxidative stress and apoptosis have not been studied.

$\mathrm{H}_{2} \mathrm{O}_{2}$ has been extensively used to induce an apoptotic response in different cell types and the $\mathrm{H} 9 \mathrm{C} 2$ cell line is frequently used to study oxidative stress induced cardiomyocyte apoptosis (21). Therefore, the aim of this present study was to investigate the effect of miR-370 on $\mathrm{H}_{2} \mathrm{O}_{2}$-induced myocardial damage in $\mathrm{H} 9 \mathrm{C} 2$ cells via oxidative stress and apoptosis.

\section{Materials and methods}

Cell culture and treatment. The $\mathrm{H} 9 \mathrm{C} 2$ cardiomyocytes were purchased from the American Type Culture Collection. Cells were cultivated in $10 \%$ fetal bovine serum (FBS; Beyotime Institute of Biotechnology) and $1 \%$ penicillin/streptomycin DMEM (Beyotime Institute of Biotechnology) and incubated at $37^{\circ} \mathrm{C}$ in an atmosphere containing $5 \% \mathrm{CO}_{2}$. The cells were subjected to $\mathrm{H}_{2} \mathrm{O}_{2}$ (50, 100 and $200 \mu \mathrm{M}$; Merck KGaA) solution in DMEM without FBS treatment for $4 \mathrm{~h}$.

Cell transfection. H9C2 cells were seeded into 12-well plates with $1 \times 10^{6}$ cells/well and cultured in serum-free DMEM at $37^{\circ} \mathrm{C}$ with $5 \% \mathrm{CO}_{2}$ continuously to ensure that cell confluence reached $80 \%$ before transfection.
According to the manufacturer's protocol, miR-370 mimics (cat. no. miR10000722-1-5), negative control (NC) mimic (cat. no. miR1190315051351), small interfering RNA (siR-/siRNA)-Forkhead box O1 (FOXO1)-1 (5'-GGACAACA ACAGTAAATTT-3'), siR-FOXO1-2 (5'-GCACCGACTTTA TGAGCAA-3') and NC siRNA (cat. no. siT0000003-1-5) (Each, $100 \mathrm{nM}$; all, Guangzhou RiboBio Co., Ltd.) were transfected into H9C2 cells for $48 \mathrm{~h}$ using Lipofectamine $2000^{\mathrm{TM}}$ reagent (Invitrogen; Thermo Fisher Scientific, Inc.).

Cell viability assay. Cell Counting Kit-8 (CCK-8; Dojindo Molecular Technologies, Inc.) was used to assess cardiomyocyte viability. After $\mathrm{H} 9 \mathrm{C} 2$ cells were treated with $\mathrm{H}_{2} \mathrm{O}_{2}, 10 \mu \mathrm{l}$ CCK-8 solution was added to each well and the cells were incubated at $37^{\circ} \mathrm{C}$ for $4 \mathrm{~h}$. Finally, the optical density of each well was measured at a wavelength of $490 \mathrm{~nm}$ using a plate reader (Infinite ${ }^{\circledR} 200$ PRO NanoQuant; Tecan Group, Ltd.).

ELISA. The concentrations of plasma superoxide dismutase (SOD; cat. no. m1077379), malondialdehyde (MDA; cat. no. m1077384) and lactate dehydrogenase (LDH, ml003416) were measured using commercial ELISA kits (Shanghai Enzyme-linked Biotechnology Co., Ltd.) according to the manufacturer's protocols. The experimental groups were as follows: Control group, $\mathrm{H} 9 \mathrm{C} 2$ cells untreated with $\mathrm{H}_{2} \mathrm{O}_{2}$; $\mathrm{H}_{2} \mathrm{O}_{2}$ group, $\mathrm{H} 9 \mathrm{C} 2$ cells treated with $\mathrm{H}_{2} \mathrm{O}_{2} ; \mathrm{NC}$ mimic $+\mathrm{H}_{2} \mathrm{O}_{2}$ group, $\mathrm{H} 9 \mathrm{C} 2$ cells treated with $\mathrm{NC}$ mimic after $\mathrm{H}_{2} \mathrm{O}_{2} ;$ miR-370 mimic $+\mathrm{H}_{2} \mathrm{O}_{2}$ group, $\mathrm{H} 9 \mathrm{C} 2$ cells treated with miR-370 mimic after $\mathrm{H}_{2} \mathrm{O}_{2} ; \mathrm{NC}$ siRNA+ $\mathrm{H}_{2} \mathrm{O}_{2}$ group, $\mathrm{H} 9 \mathrm{C} 2$ cells treated with NC siRNA after $\mathrm{H}_{2} \mathrm{O}_{2}$; and siR-FOXO1-1+ $\mathrm{H}_{2} \mathrm{O}_{2}$ group, $\mathrm{H} 9 \mathrm{C} 2$ cells treated with siR-FOXO1-1 after $\mathrm{H}_{2} \mathrm{O}_{2}$.

Flow cytometry assay. Cell apoptosis was evaluated using an Annexin V-FITC Apoptosis Detection kit (BD Biosciences; Becton, Dickson and Company) in accordance with the manufacturer's protocol. The cells were treated as described above. All adhering and floating cells were harvested, washed twice with PBS, transferred into sterile centrifuge tube and then stained successively with propidium iodide $(10 \mu \mathrm{l})$ and Annexin-V-FITC (10 $\mu$ l; Nanjing KeyGen Biotech Co., Ltd.) for $15 \mathrm{~min}$ at $37^{\circ} \mathrm{C}$. A flow cytometer (BD Biosciences; Becton, Dickson and Company) was used to assess apoptotic cells and data were analyzed using CellQuest software (version 3.1, BD Biosciences). Experiments were repeated three times independently.

Reverse transcription-quantitative PCR (RT-qPCR). Total RNA was extracted from cells using TRIzol reagent (Thermo Fisher Scientific, Inc.). Then, the total RNA was used to synthesize cDNA using a PimeScript RT master mix kit (Takara Biotechnology Co., Ltd.) following the manufacturer's protocol. The RT conditions were as follows: $10 \mathrm{~min}$ at $25^{\circ} \mathrm{C}$, $30 \mathrm{~min}$ at $45^{\circ} \mathrm{C}$ and $5 \mathrm{~min}$ at $95^{\circ} \mathrm{C}$. qPCR was performed with the following thermocycling condition: $95^{\circ} \mathrm{C}$ for an initial $10 \mathrm{~min}$ followed by 40 cycles of denaturation for $15 \mathrm{sec}$ at $95^{\circ} \mathrm{C}$, annealing at $60^{\circ} \mathrm{C}$ for $30 \mathrm{sec}$ and extension at $72^{\circ} \mathrm{C}$ for $30 \mathrm{sec}$ with the SYBR Premix Ex Taq (Applied Biosystems; Thermo Fisher Scientific, Inc.). Fold-changes of miR-370 and mRNA levels were calculated using the $2^{-\Delta \Delta \mathrm{Cq}}$ method (22). U6 and GAPDH were used as the endogenous controls. The 
following primers were used: GAPDH forward, 5'-AGACAG CCGCATCTTCTTGT-3' and reverse, 5'-TGATGGCAACAA TGTCCACT-3'; U6 forward, 5'-CTCGCTTCGGCAGCA CA-3', and reverse, 5'-AACGCTTCACGAATTTGCGT-3'; miR-370 forward, 5'-TACTCAGGATCCTGTGCAAGGCGG GCTACT-3' and reverse, 5'-TACTCAAAGCTTCCCTCCCTC ACCCAAATC-3'; FOXO1 forward, 5'-AGGATCCGATGT CACCATGGCCG-3' and reverse, 5'-AAAGGATCCACCATG GCCG-3'.

Western blot analysis. The total proteins from cells were isolated using RIPA lysis buffer (Beyotime Institute of Biotechnology) and the concentration of protein was measured with a bicinchoninic acid kit (Beyotime Institute of Biotechnology). Subsequently, an equal quantity of proteins $(20 \mu \mathrm{g})$ was separated by $10 \%$ SDS-PAGE and then transferred onto polyvinylidene fluoride membranes (EMD Millipore). Then the membranes were blocked with 5\% non-fat dry milk for $1 \mathrm{~h}$ at room temperature. After washing, the membranes were incubated with primary antibodies against FOXO1 (1:1,000; cat. no. 2880) and GAPDH (1:2,000; cat. no. 5174) from Cell Signaling Technology, Inc. at $4^{\circ} \mathrm{C}$ overnight and washed with $0.1 \%$ Tris-Buffered Saline with Tween 20, followed by incubation with horseradish peroxidase conjugated secondary antibodies (1:3,000; cat. no. ab214880; Abcam) for $1 \mathrm{~h}$ at room temperature. Blots were developed using an enhanced chemiluminescence film kit (Perkin Elmer, Inc.) and the images were analyzed using ImageJ software (version 1.8.0; National Institutes of Health). All experiments were repeated three times independently.

Dual luciferase reporter assays. The online bioinformatics tool, TargetScan (http://www.targetscan.org/vert_71/), was used to predict the possible binding targets of miR-370 and FOXO1. A fragment of the FOXO1-3' untranslated region (UTR) containing the miR-370 predicted seed region (wild-type; WT) was amplified from the cDNA of cells and inserted into pGL-3 plasmids (Promega Corporation). The H9C2 cells were co-transfected with the WT 3'UTR of FOXO1 containing the miR-370 binding sites and mutant FOXO1 3'UTR with NC mimics or miR-370 mimics using Lipofectamine $2000^{\mathrm{TM}}$ (Thermo Fisher Scientific, Inc.). Luciferase activity was measured by the Dual Luciferase Reporter Assay system (Promega Corporation), normalizing to Renilla luciferase activity. All experiments were repeated three times independently.

Statistical analysis. All data were presented as the mean \pm standard deviation. SPSS v20.0 software (IBM Corp.) was used to analyze the data. Additionally, a Student's t-test was used to determine differences between two groups, while one-way analysis of variance followed by the Dunnett's post hoc test were used for multiple comparisons. $\mathrm{P}<0.05$ was considered to indicate a statistically significant difference.

\section{Results}

Cell viability and the expression of miR-370 are inhibited by $\mathrm{H}_{2} \mathrm{O}_{2}$ in cardiomyocytes. The $\mathrm{H} 9 \mathrm{C} 2$ cells were treated with $\mathrm{H}_{2} \mathrm{O}_{2}$ at different concentrations $(0,50,100$ and $200 \mu \mathrm{mol} / \mathrm{l})$

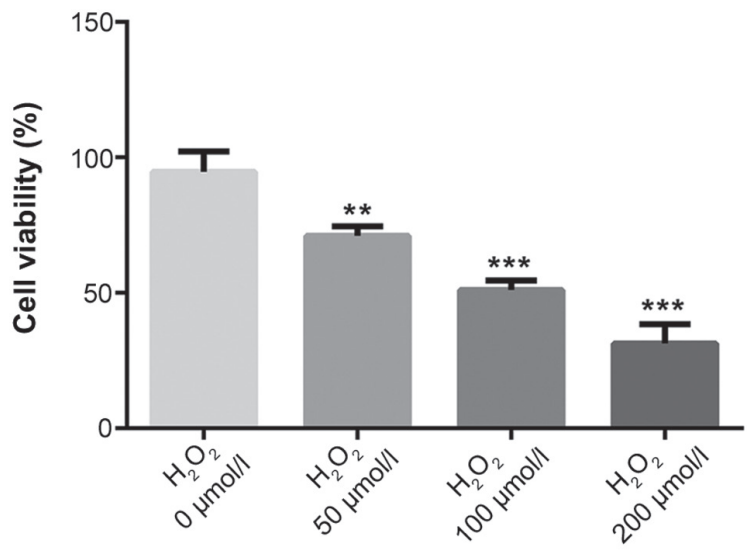

Figure 1. Cell viability is inhibited by $\mathrm{H}_{2} \mathrm{O}_{2}$ in $\mathrm{H} 9 \mathrm{C} 2$ cells. Cell viability was detected by a Cell Counting Kit- 8 assay. Three independent experiments were carried out. Error bars represent the mean \pm standard deviation of at least three independent experiments ${ }^{* *} \mathrm{P}<0.01$ and ${ }^{* * * *} \mathrm{P}<0.001$ vs. control. $\mathrm{H}_{2} \mathrm{O}_{2}$, hydrogen peroxide.

for $4 \mathrm{~h}$. Then, the cell viability was detected using a CCK-8 assay. As shown in Fig. 1, when compared with the control $\left(0 \mu \mathrm{mol} / 1 \mathrm{H}_{2} \mathrm{O}_{2}\right)$ group, the activity of $\mathrm{H} 9 \mathrm{C} 2$ cells treated with oxidative stress was concentration dependent and cell viability significantly decreased with the increasing concentration $(\mathrm{P}<0.01)$. A dose of $100 \mu \mathrm{mol} / \mathrm{l}$ (cell viability, 50\%) was selected for subsequent experiments.

miR-370 overexpression attenuates $\mathrm{H}_{2} \mathrm{O}_{2}$-induced oxidative stress and apoptosis in $\mathrm{H} 9 \mathrm{C} 2$ cells. The $\mathrm{H}_{2} \mathrm{O}_{2}$-induced $\mathrm{H} 9 \mathrm{C} 2$ cells were transfected with the miR-370 mimic or NC mimic vectors. Subsequently, RT-qPCR was performed to detect the expression levels of miR-370. As shown in Fig. 2A, the expression of miR-370 was significantly decreased in the $\mathrm{H}_{2} \mathrm{O}_{2}$-induced $\mathrm{H} 9 \mathrm{C} 2$ cells when compared with the normal H9C 2 cells $(\mathrm{P}<0.001)$; however, the expression of miR-370 was significantly increased in $\mathrm{H} 9 \mathrm{C} 2$ cells transfected with miR-370 mimic when compared with the NC mimic group $(\mathrm{P}<0.001$; Fig. 2A). The results indicated that miR-370 expression could be inhibited by $\mathrm{H}_{2} \mathrm{O}_{2}$ in $\mathrm{H} 9 \mathrm{C} 2$ cells, which in turn suggested that miR-370 may be downregulated in myocardial cells with ischemia and hypoxia.

To verify miR-370 function in oxidative stress and apoptosis, an ELISA was used to detect SOD, MDA and LDH levels in the supernatant, and a flow cytometry assay was used to detect apoptosis. As exhibited in Fig. 2B, when compared with the control group, SOD expression significantly decreased $(\mathrm{P}<0.001)$ and $\mathrm{MDA}$ and $\mathrm{LDH}$ expression significantly increased in the $\mathrm{H}_{2} \mathrm{O}_{2}$ and $\mathrm{NC}$ mimic groups $(\mathrm{P}<0.01)$. Compared with the $\mathrm{H}_{2} \mathrm{O}_{2}$ and $\mathrm{NC}$ mimic groups, SOD expression increased, and MDA and LDH expression reduced in the miR-370 mimics group. Furthermore, the results of flow cytometry revealed that the rate of apoptosis was significantly increased in the $\mathrm{H}_{2} \mathrm{O}_{2}$ and $\mathrm{NC}$ mimic groups when compared with the control group $(\mathrm{P}<0.001$; Fig. 2C and D). Compared with the $\mathrm{H}_{2} \mathrm{O}_{2}$ and $\mathrm{NC}$ mimic groups, the rate of apoptosis was decreased in the miR-370 mimics group. These findings suggested that the overexpression of miR-370 could markedly suppress the oxidative stress and apoptosis induced by $\mathrm{H}_{2} \mathrm{O}_{2}$. 
A

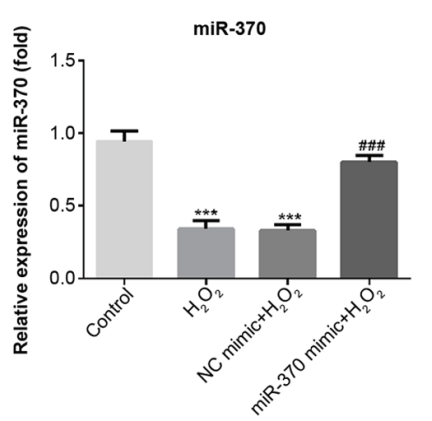

C

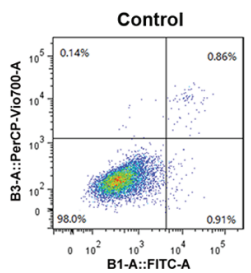

B

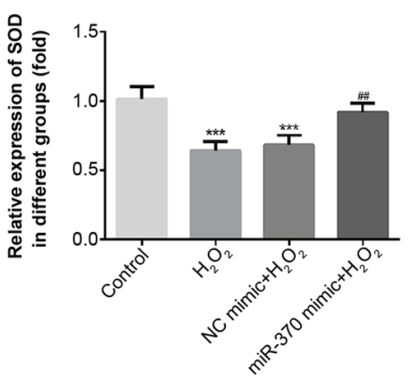

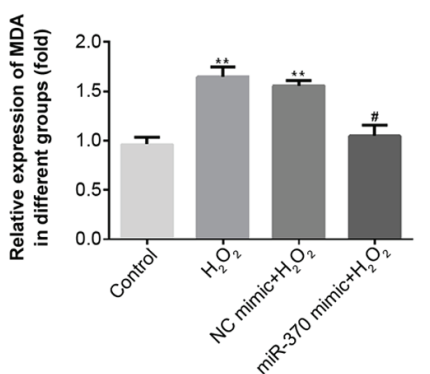

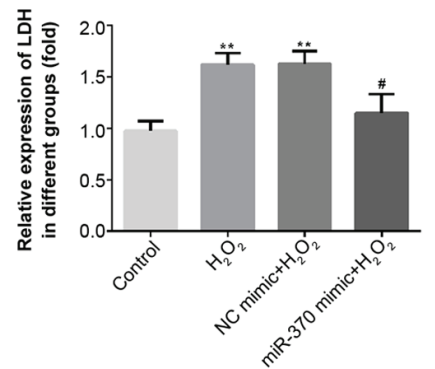

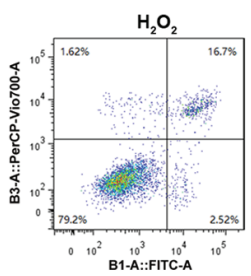
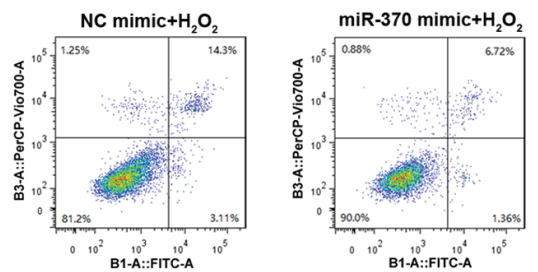

D

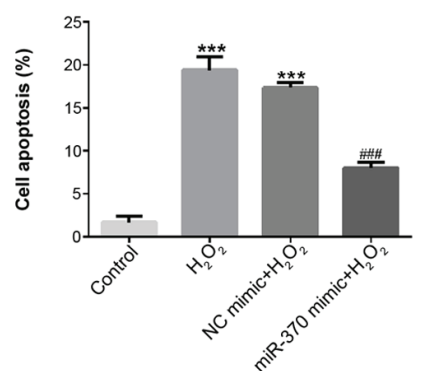

Figure 2. miR-370 overexpression attenuates $\mathrm{H}_{2} \mathrm{O}_{2}$-induced oxidative stress and apoptosis in $\mathrm{H} 9 \mathrm{C} 2$ cells. (A) The expression of miR-370 was detected by reverse transcription-quantitative PCR upon transfection of $\mathrm{H}_{2} \mathrm{O}_{2}$-induced $\mathrm{H} 9 \mathrm{C} 2$ cells with NC and miRNA-370 mimics. (B) The activity of SOD, LDH and MDA in $\mathrm{H}_{2} \mathrm{O}_{2}$-induced $\mathrm{H} 9 \mathrm{C} 2$ cells was determined by ELISA. (C) After transfection with miR-370 or NC mimics, $\mathrm{H} 9 \mathrm{C} 2$ cells were determined by Annexin-V-FITC/propidium iodide staining. (D) Percentage of apoptotic cell death. Three independent experiments were carried out. Error bars represent the mean \pm standard deviation of at least three independent experiments. ${ }^{* * *} \mathrm{P}<0.01$ and ${ }^{* * *} \mathrm{P}<0.001$ vs. control; ${ }^{\#} \mathrm{P}<0.05$, ${ }^{\# \#} \mathrm{P}<0.01$ and ${ }^{\# \# *} \mathrm{P}<0.001$ vs. $\mathrm{H}_{2} \mathrm{O}_{2}$ group $\mathrm{H}_{2} \mathrm{O}_{2}$, hydrogen peroxide; miR-370, microRNA-370; NC, negative control; SOD, superoxide dismutase; LDH, lactate dehydrogenase; MDA, malondialdehyde; FITC, fluorescein isothiocyanate.

A

FOXO1 miR-370-3p

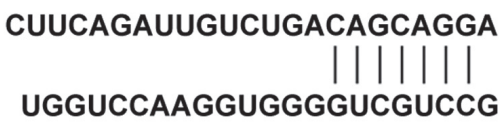

B

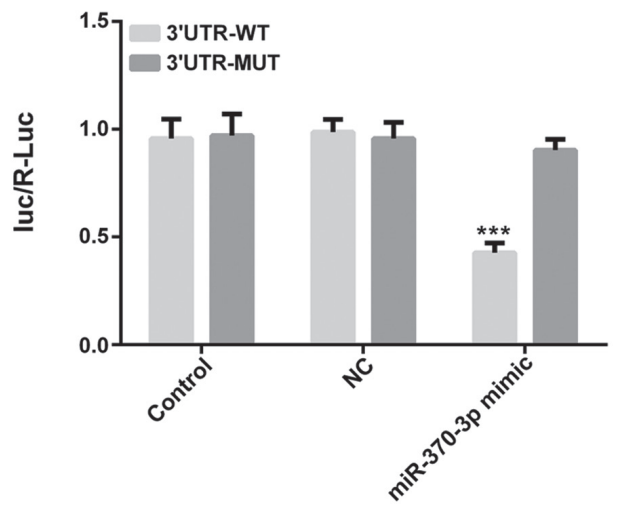

Figure 3. FOXO1 is a target gene of miR-370. (A) Human FOXO1 3'-UTR containing the WT or MUT type miR-370 binding site was cloned into the miRNA expression vector. FOXO1 was predicted as the target gene of miR-370 by TargetScan. (B) H9C2 cells were co-transfected with WT or MT plasmids and miR-370 or miR-control (miR-NC) and luciferase activity was then detected using a luciferase reporter assay. Three independent experiments were conducted. Error bars represent the mean \pm standard deviation of at least three independent experiments. ${ }^{* * *} \mathrm{P}<0.001 \mathrm{vs}$. the UTR-MUT miR-370 group. miR-370, microRNA-370; FOXO1, Forkhead box O1; UTR, untranslated region; WT, wild type; MUT, mutant; miRNA, microRNA; NC, negative control.

Luciferase reporter assay for target verification. The results of the online bioinformatics tool TargetScan suggested that FOXO1 was predicted to be a possible target gene of miR-370.
A luciferase reporter assay was conducted to verify this prediction. As shown in Fig. 3, the 3'-UTR of the gene FOXO1 was shown to contain the binding sequences for miR-370, suggesting that FOXO1 may be a downstream target gene of miR-370. Luciferase activity was significantly reduced in the FOXO1 3'UTR WT group transfected with miR-370-3p mimics $(\mathrm{P}<0.001)$, whereas there was no variation in the mutant-type FOXO1 3'UTR, therefore also suggesting that FOXO1 may be a direct target gene of miR-370.

FOXOl expression is increased in $\mathrm{H}_{2} \mathrm{O}_{2}$-induced $\mathrm{H} 9 \mathrm{C} 2$ cells. The mRNA and protein levels of FOXO1 were measured by RT-qPCR and western blotting assay. As shown in Fig. $4 \mathrm{~A}$ and $\mathrm{B}$, the expression of FOXO1 was markedly increased in the $\mathrm{H}_{2} \mathrm{O}_{2}$ and $\mathrm{NC}$ mimic groups when compared with the control group. Compared with the $\mathrm{H}_{2} \mathrm{O}_{2}$ and $\mathrm{NC}$ mimic groups, FOXO1 expression was decreased in the miR-370 mimic group. Then, the interference efficiency of FOXO1 siRNA plasmids was detected using RT-qPCR and western blot assays. As shown in Fig. 4C and D, the expression of FOXO1 was significantly reduced in the siR-FOXO-1 and siR-FOXO1-2 groups when compared with the NC siRNA group $(\mathrm{P}<0.001)$. The siR-FOXO1-1 plasmid with the best interference effects was selected for subsequent experiments.

FOXO1 silencing inhibits oxidative stress and apoptosis in $\mathrm{H}_{2} \mathrm{O}_{2}$-induced $\mathrm{H} 9 \mathrm{C} 2$ cells. ELISA was used to detect the levels of SOD, MDA and LDH in the supernatant, and a flow cytometry assay was used to detect apoptosis in $\mathrm{H}_{2} \mathrm{O}_{2}$-induced H9C2 cells. As shown in Fig. 5A, compared with the control group, the level of SOD significantly decreased $(\mathrm{P}<0.001)$ and 
A

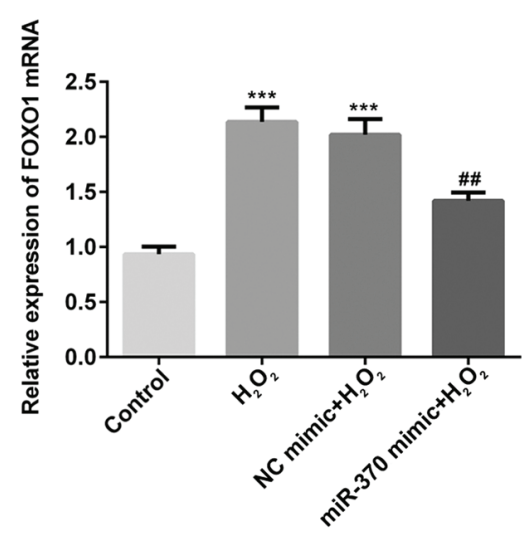

C

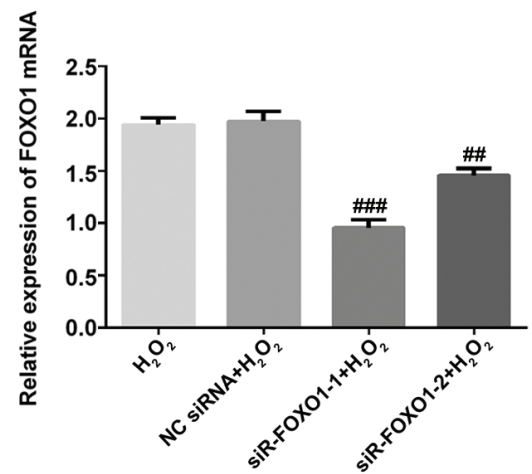

B
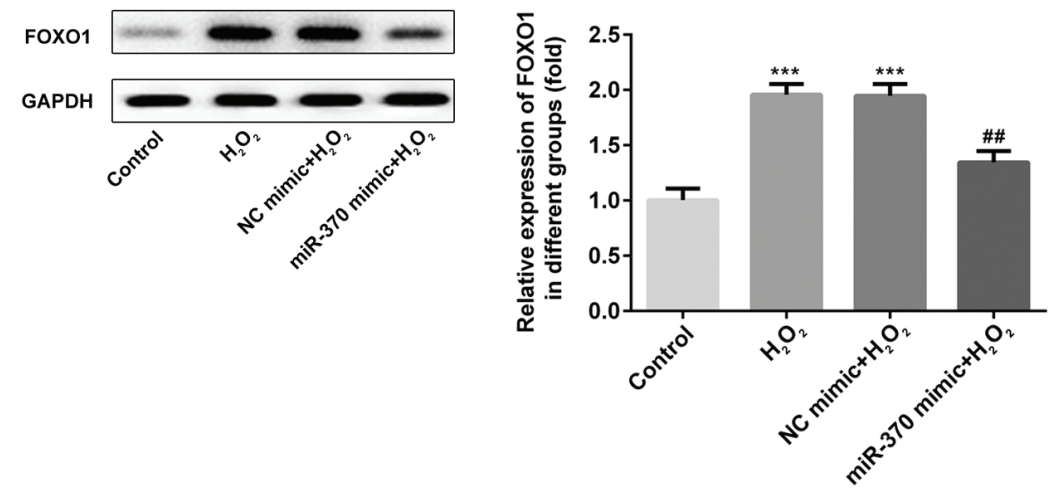

D

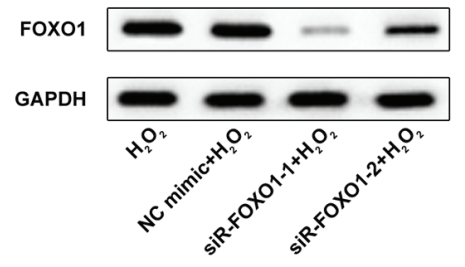

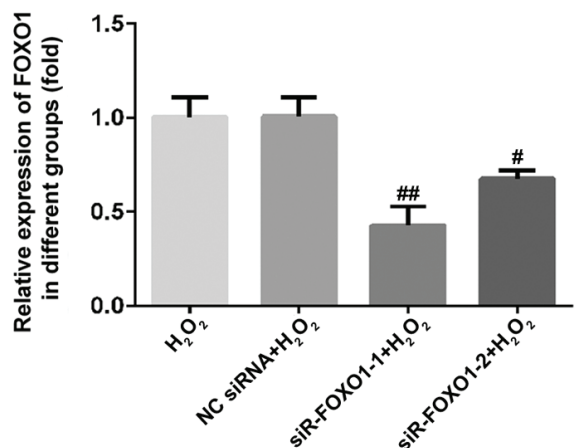

Figure 4. FOXO1 expression is increased in $\mathrm{H}_{2} \mathrm{O}_{2}$-induced $\mathrm{H} 9 \mathrm{C} 2$ cells. (A) RT-qPCR and (B) western blot analysis were performed to detect the mRNA and protein levels of FOXO1 in different group. ${ }^{* * *} \mathrm{P}<0.001$ vs. control; ${ }^{\# /} \mathrm{P}<0.01$ vs. $\mathrm{H}_{2} \mathrm{O}_{2}$ group. After treatment with $\mathrm{H}_{2} \mathrm{O}_{2}, \mathrm{H} 9 \mathrm{C} 2$ cells were transfected with siR-FOXO1-1, siR-FOXO1-2 and NC siRNA plasmids. The interference efficiency was measured by (C) RT-qPCR and (D) western blotting in the siR-FOXO1-1 and siR-FOXO1-2 groups. ${ }^{\#} \mathrm{P}<0.05,{ }^{\# \#} \mathrm{P}<0.01$ and ${ }^{\# \# \#} \mathrm{P}<0.001$ vs. $\mathrm{H}_{2} \mathrm{O}_{2}$ group. Three independent experiments were carried out. Error bars represent the mean \pm standard deviation of at least three independent experiments. FOXO1, Forkhead box O1; siRNA/siR, small interfering RNA; NC, negative control; $\mathrm{H}_{2} \mathrm{O}_{2}$, hydrogen peroxide; RT-qPCR, reverse transcription-quantitative PCR.

the levels of MDA and LDH were significantly increased in the $\mathrm{H}_{2} \mathrm{O}_{2}$ and $\mathrm{NC}$ siRNA groups $(\mathrm{P}<0.001)$. However, compared with the $\mathrm{H}_{2} \mathrm{O}_{2}$ and $\mathrm{NC}$ siRNA groups, SOD expression significantly increased $(\mathrm{P}<0.01)$, and MDA and $\mathrm{LDH}$ expression significantly decreased in the siR-FOXO1-1 group $(\mathrm{P}<0.01)$. The results of flow cytometry revealed that the rate of apoptosis was significantly increased in the $\mathrm{H}_{2} \mathrm{O}_{2}$ and $\mathrm{NC}$ siRNA groups when compared with the control group $(\mathrm{P}<0.001$; Fig. 5B and C). In addition, compared with the $\mathrm{H}_{2} \mathrm{O}_{2}$ and $\mathrm{NC}$ siRNA groups, the rate of apoptosis was significantly decreased in the siR-FOXO1-1 group $(\mathrm{P}<0.01)$. These results suggested that knockdown of FOXO1 could markedly suppress the oxidative stress and apoptosis of $\mathrm{H} 9 \mathrm{C} 2$ cells induced by $\mathrm{H}_{2} \mathrm{O}_{2}$.

\section{Discussion}

The results of the present study revealed that the expression of miR-370 was decreased in $\mathrm{H}_{2} \mathrm{O}_{2}$-induced $\mathrm{H} 9 \mathrm{C} 2$ cells. In addition, miR-370 overexpression attenuated $\mathrm{H}_{2} \mathrm{O}_{2}$-induced oxidative stress and apoptosis in $\mathrm{H} 9 \mathrm{C} 2$ cells. Nevertheless, the underlying mechanism of miR-370 in ischemic heart disease remains largely unknown. In vitro experiments are required to further explore the effect of miR-370, in order to provide the theoretical basis for the research.

After maturation, miRNA can regulate gene expression via complementation with target mRNA and regulating cell differentiation proliferation, metabolism, and apoptosis (23-26). It has been indicated that miR-370 is involved in various types of heart diseases $(27,28)$. A number of studies have published their results on miR-370 in cardiovascular diseases; however, the results are controversial. A previous study reported that miR-370 was significantly higher in patients with coronary artery disease (29). Additionally, miR-370 was reported to be upregulated in peripheral blood mononuclear cells of coronary AS patients (30). By contrast, miR-370 has also been found to have a positive effect in different diseases. Consistent with a previous study, the expression level of miR-370 markedly decreased in AS mouse models and oxidized low-density lipoprotein incubated THP-1 cells, and miR-370 overexpression inhibited vascular inflammation and oxidative stress (19). In myocardial remodeling, the expression of miR-370 in the infarct border area was decreased after MI, but myocardial fibrosis was suppressed through the intervention of miR-370 (20). The positive role of miR-360 is consistent with the results of the present study, the expression of miR-370 was markedly decreased in $\mathrm{H} 9 \mathrm{C} 2$ cells induced by $\mathrm{H}_{2} \mathrm{O}_{2}$.

In the present study, $\mathrm{H}_{2} \mathrm{O}_{2}$ had proapoptotic effects on $\mathrm{H} 9 \mathrm{C} 2$ cells. Hypoxia is the main cause of ischemic heart disease which leads to autophagy and apoptosis through the activation of a caspase cascade via the release of cytochrome $\mathrm{c}$ from the mitochondria to the cytoplasm (31). $\mathrm{H}_{2} \mathrm{O}_{2}$ activated oxidative stress through the downregulation of SOD levels and upregulation of MDA and LDH levels in the present study. In addition, $\mathrm{H}_{2} \mathrm{O}_{2}$ induced apoptosis by downregulating $\mathrm{Bcl}-2$ and upregulating 
A

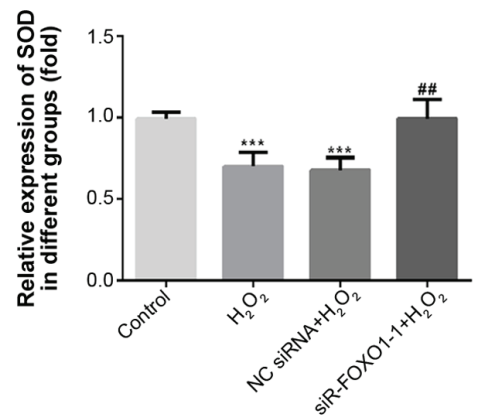

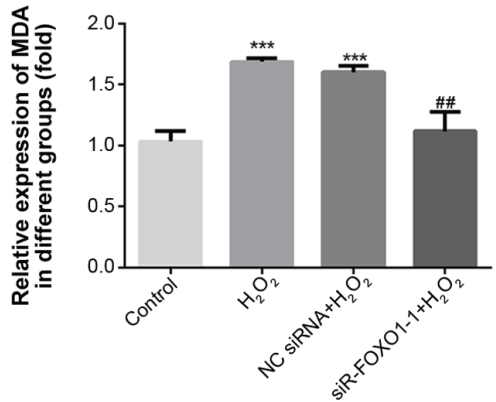

B
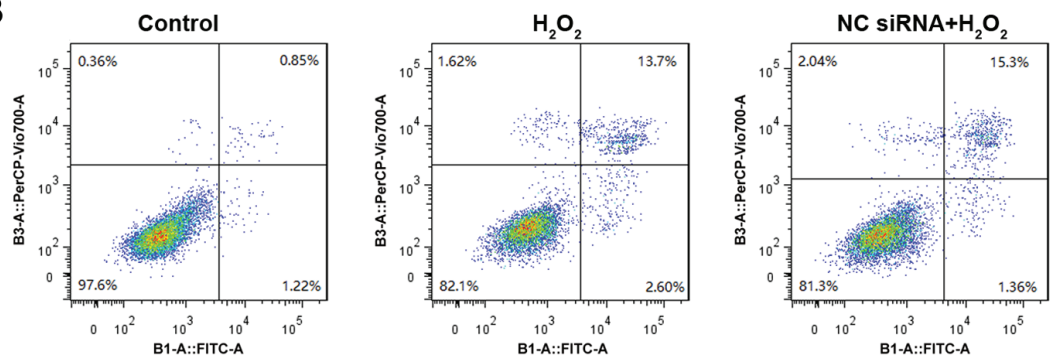

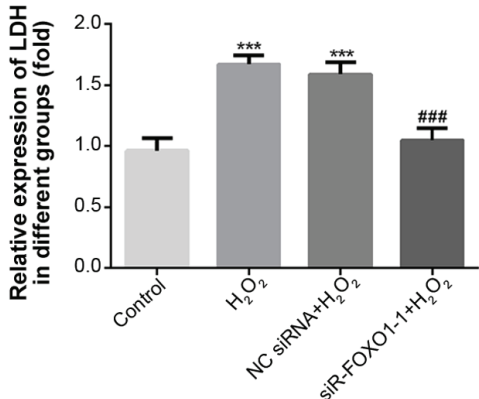

C

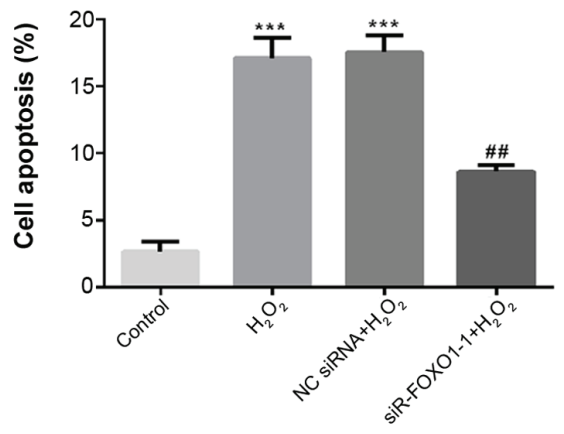

Figure 5. Effect of FOXO1 silencing on oxidative stress and apoptosis levels in $\mathrm{H} 9 \mathrm{C} 2$ cells. After treatment with $\mathrm{H}_{2} \mathrm{O}_{2}$, $\mathrm{H} 9 \mathrm{C} 2$ cells were transfected with siR-FOXO1-1 and NC siRNA plasmids. (A) The oxidative status markers including SOD, MDA and LDH were detected by ELISA. (B) Apoptosis was evaluated using a flow cytometer. (C) The percentage of apoptotic cells. ${ }^{* * *} \mathrm{P}<0.001$ vs. control; ${ }^{\# \#} \mathrm{P}<0.01$ and ${ }^{\# \#} \mathrm{P}<0.001$ vs. $\mathrm{H}_{2} \mathrm{O}_{2}$ group. Three independent experiments were conducted. Error bars represent the mean \pm standard deviation of at least three independent experiments. SOD, superoxide dismutase; LDH, lactate

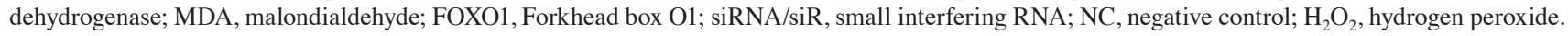

the expression of proapoptotic proteins, such as Bax, caspase-8, and cleaved-caspase-3 (32). Oxidative stress and apoptosis are involved in cardiovascular diseases. For example, the overexpression of miRNA-132 increased the anti-oxidative stress and anti-apoptotic abilities of H9C2 cells in heart failure (33). The present study demonstrated that overexpression of miR-370 suppressed the oxidative stress and apoptosis induced by $\mathrm{H}_{2} \mathrm{O}_{2}$.

FOXO1 is an essential regulator of endothelial cell proliferation and can be modulated by a number of signaling pathways (34). In osteoblasts, FOXO1 expression was increased when induced by $\mathrm{H}_{2} \mathrm{O}_{2}$ (35). Therefore, the present study speculated that FOXO1 may also be involved in the apoptosis of cardiac myocytes induced by oxidative stress. TargetScan analysis suggested that transcription factor FOXO1 was a possible target gene of miR-370. As the results demonstrated, FOXO1 expression was increased in $\mathrm{H} 9 \mathrm{C} 2$ cells induced by $\mathrm{H}_{2} \mathrm{O}_{2}$. Furthermore, FOXO1 silencing suppressed $\mathrm{H}_{2} \mathrm{O}_{2}$-induced oxidative stress and apoptosis in $\mathrm{H} 9 \mathrm{C} 2$ cells. These results indicated that FOXO1 was involved in $\mathrm{H}_{2} \mathrm{O}_{2}$-induced oxidative stress and apoptosis, which was consistent with the hypothesis of the present study.
However, some limitations should be considered in the present study, the $\mathrm{H} 9 \mathrm{C} 2$ cells are not mature cardiomyocytes and only an in vitro model, which does not entirely explain the results in physiological and pathological processes. Therefore, future studies will be needed to confirm the present results in IR with in vivo models.

In conclusion, the results of the present study indicate that FOXO1 was a target gene of miR-370, and miR-370 reduced $\mathrm{H}_{2} \mathrm{O}_{2}$-induced oxidative stress and apoptosis in $\mathrm{H} 9 \mathrm{C} 2$ cells by targeting FOXO1, which provides a theoretical basis for the treatment of ischemic heart disease.

\section{Acknowledgements}

Not applicable.

\section{Funding}

The present study was supported by the Shandong Medical and Health Science and Technology Development Plan Project (grant no. 2018WS193), Science and the Technology 
Development Plan Project of Jinan (grant no. 201602184), and the Shandong Province TCM Science and Technology Development Plan (grant no. 2015-091).

\section{Availability of data and materials}

The datasets used and/or analyzed during the current study are available from the corresponding authors on reasonable request.

\section{Authors' contributions}

ZJQ, LW, LNW and YGC designed the research. ZJQ, LW, HYM, FX and BS performed the experiments. ZJQ, LW, XBL, JLW and FK analyzed the data. ZJQ, LW, HYM and FX drafted the manuscript and analyzed data. LNW and YGC interpreted data and revised the final manuscript. ZJQ and LW wrote the manuscript. All authors read and approved the final manuscript.

\section{Ethics approval and consent to participate}

Not applicable.

\section{Patient consent for publication}

Not applicable.

\section{Competing interests}

The authors declare that they have no competing interests.

\section{References}

1. Poole-Wilson P: The prevention of cardiovascular disease worldwide: Whose task and WHO's task? Clini Med (Lond) 5: 379-384, 2005.

2. Porter KE and Turner NA: Cardiac fibroblasts: At the heart of myocardial remodeling. Pharmacol Ther 123: 255-278, 2009.

3. Qiu H, Liu JY, Wei D, Li N, Yamoah EN, Hammock BD and Chiamvimonvat N: Cardiac-generated prostanoids mediate cardiac myocyte apoptosis after myocardial ischaemia. Cardiovasc Res 95: 336-345, 2012.

4. Katz AM and Messineo FC: Lipid-membrane interactions and the pathogenesis of ischemic damage in the myocardium. Circ Res 48: 1-16, 1981.

5. Abbate A and Narula J: Role of apoptosis in adverse ventricular remodeling. Heart Fail Clin 8: 79-86, 2012.

6. Navarro-Yepes J, Burns M, Anandhan A, Khalimonchuk O, del Razo LM, Quintanilla-Vega B, Pappa A, Panayiotidis MI and Franco R: Oxidative stress, redox signaling, and autophagy: Cell death versus survival. Antioxid Redox Signal 21: 66-85, 2014.

7. Morales CR, Pedrozo Z, Lavandero S and Hill JA: Oxidative stress and autophagy in cardiovascular homeostasis. Antioxid Redox Signal 20: 507-518, 2014.

8. Ogura $\mathrm{S}$ and Shimosawa T: Oxidative stress and organ damages. Curr Hypertens Rep 16: 452, 2014.

9. Farias JG, Molina VM, Carrasco RA, Zepeda AB, Figueroa E, Letelier P and Castillo RL: Antioxidant therapeutic strategies for cardiovascular conditions associated with oxidative stress. Nutrients 9: pii: E966, 2017.

10. Brown DI and Griendling KK: Regulation of signal transduction by reactive oxygen species in the cardiovascular system. Circ Res 116: 531-549, 2015.

11. Krol J, Loedige I and Filipowicz W: The widespread regulation of microRNA biogenesis, function and decay. Nat Rev Genet 11: 597-610, 2010

12. Guo H, Ingolia NT, Weissman JS and Bartel DP: Mammalian microRNAs predominantly act to decrease target mRNA levels. Nature 466: 835-840, 2010.
13. Baek D, Villen J, Shin C, Camargo FD, Gygi SP and Bartel DP: The impact of microRNAs on protein output. Nature 455: 64-71, 2008.

14. Orenes-Pinero E, Montoro-Garcia S, Patel JV, Valdes M, Marin F and Lip GY: Role of microRNAs in cardiac remodelling: New insights and future perspectives. Int J Cardiol 167: 1651-1659, 2013.

15. JoladarashiD, Thandavarayan RA,Babu SS and Krishnamurthy P: Small engine, big power: microRNAs as regulators of cardiac diseases and regeneration. Int J Mol Sci 15: 15891-8911, 2014.

16. Chen C, Ponnusamy M, Liu C, Gao J, Wang K and Li P: MicroRNA as a therapeutic target in cardiac remodeling. Biomed Res Int 2017: 1278436, 2017.

17. Chen XP, Chen YG, Lan JY and Shen ZJ: MicroRNA-370 suppresses proliferation and promotes endometrioid ovarian cancer chemosensitivity to cDDP by negatively regulating ENG. Cancer Lett 353: 201-210, 2014

18. Feng Y, Sun T, Yu Y, Gao Y, Wang X and Chen Z: MicroRNA-370 inhibits the proliferation, invasion and EMT of gastric cancer cells by directly targeting PAQR4. J Pharmacol Sci 138: 96-106, 2018.

19. Tian D, Sha Y, Lu JM and Du XJ: MiR-370 inhibits vascular inflammation and oxidative stress triggered by oxidized low-density lipoprotein through targeting TLR4. J Cell Biochem 119: 6231-6237, 2018.

20. Yuan $\mathrm{H}$ and Gao J: The role of miR370 in fibrosis after myocardial infarction. Mol Med Rep 15: 3041-3027, 2017.

21. Wu H, Gao H, Gao S, Lei Z, Dai L, Wang X, Han Y, Wang Z and Han L: A Chinese 4-herb formula, Yiqi-Huoxue granule, alleviates $\mathrm{H}_{2} \mathrm{O}_{2}$-induced apoptosis by upregulating uncoupling protein 2 in H9c2 cells. Phytomedicine 53: 171-181, 2019.

22. Livak KJ and Schmittgen TD: Analysis of relative gene expression data using real-time quantitative PCR and the 2(-Delta Delta C(T)) method. Methods 25: 402-408, 2001.

23. $\mathrm{Xu} \mathrm{G}, \mathrm{Zhu} \mathrm{H}, \mathrm{Zhang} \mathrm{M}$ and $\mathrm{Xu} \mathrm{J}$ : Histone deacetylase 3 is associated with gastric cancer cell growth via the miR-454-mediated targeting of CHD5. Int J Mol Med 41: 155-163, 2018.

24. Qi R, Huang J, Wang Q, Liu H, Wang R, Wang J and Yang F: MicroRNA-224-5p regulates adipocyte apoptosis induced by TNFo via controlling NF- $\kappa \mathrm{B}$ activation. J Cell Physiol 233: 1236-1246, 2018.

25. Wu J, He D, Yue B, Zhang C, Fang X and Chen H: miR-101-1 expression pattern in Qinchuan cattle and its role in the regulation of cell differentiation. Gene 636: 64-69, 2017.

26. Zhang K and Guo L: MiR-767 promoted cell proliferation in human melanoma by suppressing CYLD expression. Gene 641: 272-278, 2018.

27. Tian D, Sha Y, Lu JM and Du XJ: MiR-370 inhibits vascular inflammation and oxidative stress triggered by oxidized low-density lipoprotein through targeting TLR4. J Cell Biochem 119: 6231-6237, 2018.

28. Yuan $\mathrm{H}$ and Gao J: The role of miR-370 in fibrosis after myocardial infarction. Mol Med Rep 15: 3041-3047, 2017.

29. Liu H, Yang N, Fei Z, Qiu J, Ma D, Liu X, Cai G and Li S: Analysis of plasma miR-208a and miR-370 expression levels for early diagnosis of coronary artery disease. Biomed Rep 5: 332-336, 2016.

30. Hoekstra M, van der Lans CA, Halvorsen B, Gullestad L, Kuiper J, Aukrust P, van Berkel TJ and Biessen EA: The peripheral blood mononuclear cell microRNA signature of coronary artery disease. Biochem Biophys Res Commun 394: 792-797, 2010.

31. Hu J, Chu Z, Han J, Zhang Q, Zhang D, Dang Y, Ren J, Chan HC, Zhang J and Huang Y: Phosphorylation-dependent mitochondrial translocation of MAP4 is an early step in hypoxia-induced apoptosis in cardiomyocytes. Cell Death Dis 5: e1424, 2014.

32. Chang H, Li C, Huo K, Wang Q, Lu L, Zhang Q, Wang Y and Wang W: Luteolin prevents $\mathrm{H} 2 \mathrm{O} 2$-induced apoptosis in $\mathrm{H} 9 \mathrm{C} 2$ cells through modulating Akt-P53/Mdm2 signaling pathway. Biomed Res Int 2016: 5125836, 2016.

33. Liu X, Tong Z, Chen K, Hu X, Jin H and Hou M: The role of miRNA-132 against apoptosis and oxidative stress in heart failure. Biomed Res Int 2018: 3452748, 2018.

34. Wilhelm K, Happel K, Eelen G, Schoors S, Oellerich MF, Lim R, Zimmermann B, Aspalter IM, Franco CA, Boettger T, et al: FOXO1 couples metabolic activity and growth state in the vascular endothelium. Nature 529: 216-220, 2016.

35. Wang Z, Ji G, Wu Q, Feng S, Zhao Y, Cao Z and Tao C: Integrated microarray meta-analysis identifies miRNA-27a as an oncogene in ovarian cancer by inhibiting FOXO1. Life Sci 210: 263-270, 2018. 